\title{
DIY PLTL: Funding the Program of the Leaders by the Leaders
}

James E. Becvar

University of Texas at El Paso

jbecvar@utep.edu

Geoffrey B. Saupe

University of Texas at El Paso

gsaupe@,utep.edu

\section{Recommended Citation}

Becvar, J.E., \& Saupe, G.B. (2021). DIY PLTL: Funding the Program of the Leaders by the Leaders. Advances in Peer-Led Learning, 1, 142-154. Online at https://doi.org/10.54935/apll2021-01-12-142 


\title{
DIY PLTL: Funding the Program of the Leaders by the Leaders
}

\author{
James E. Becvar* and Geoffrey B. Saupe** \\ Department of Chemistry and Biochemistry \\ University of Texas at El Paso \\ El Paso, Texas 79968 \\ *jbecvar@utep.edu \\ **gsaupe@utep.edu
}

\begin{abstract}
We present and describe a Do-It-Yourself strategy to develop and utilize trained Peer Leaders in your PLTL program to fund that very program. We discuss how you can develop a selffunding PLTL program by employing existing talent, creativity, and need for customized PLTL learning materials to financially support a future or current PLTL intervention. A local non-profit publisher, organized specifically for the purpose, is essential in this endeavor. The non-profit organization handles finances and provides Conflict of Interest distancing for faculty and student PLTL practitioners. To date, the non-profit and DIY-PLTL strategy described here has donated a total of more than $\$ 700,000$ to two university campus PLTL programs in support of peer-facilitated learning.
\end{abstract}

Key Words: Peer Leaders, Peer-Led Team Learning, Workshop, Non-Profit Funding, Intellectual Property, Books, Workbooks 


\section{$\underline{\text { Introduction }}$}

Do-It-Yourself Peer-Led Team Learning (DIY PLTL) represents a proven strategy to use the creative strengths of young, vibrant, very capable student entrepreneurs to help solve a problem vexing many STEM, STEAM, and STEMM facilitated-learning initiatives: how to develop and sustain the program with or without grant funding. Most universities do not have and do not provide adequate monetary funds for undergraduate facilitators of learning. Once you and your Peer Leaders (Leaders) learn this intellectual property (IP)-generation process, you will appreciate how DIY PLTL can fund your PLTL program and acquire an annual momentum that perpetuates itself. With DIY PLTL, the PLTL program becomes financially sustainable with the help of the Leaders.

The use of a non-profit to support Peer Leaders was suggested by a Peer Leader (Zonoozi et al., 2013) and was the inspiration for this DIY process. The DIY PLTL strategy described here can be used on any campus and used with other forms of peer-assisted learning. We encourage you to implement our model on your campus.

The solution to sustainability lies with the Leaders themselves. At the University of Texas at El Paso (UTEP), the year 2021 marks the $21^{\text {st }}$ anniversary of implementation of PLTL in chemistry (Becvar, 2012; Gosser \& Roth, 1998). At UTEP, PLTL has dramatically improved grades in general chemistry, increased majors in chemistry and biochemistry, boosted retention rates, and led to improved graduation rates in STEM disciplines (Becvar et al., 2008; Darnell, et al., 2013; Dreyfuss, et al., 2015; Moreno, et al., 2013). In general, the fifty Peer Leaders in this robust program are consistently creating content and contributing to the program's growth and stability. For example, this rich soil for growing intellectual property and elevating the program has generated a multitude of:

- Activities for Learning (e.g., Chacon, et al., 2009; Frederick \& Becvar, 2012; Orozco, et al., 2018),

- Games (e.g., Azam, et al., 2012a; Azam, et al., 2012b; Azam, et al., 2012c; Ramirez, et al., 2009; Ramirez, et al., 2016; Ulloa \& Becvar, 2012), and

- Strategies (e.g., Amaya, 2012; Deemer, et al., 2012; Guzman, 2016; Kerstiens, et al., 2017; Llanes et al., 2012; Ramirez, et al., 2017).

An existing vibrant PLTL program has creative and extremely capable young Leaders who can and will freely generate effective learning materials that can be used to financially support their own PLTL Program (Becvar, et al., 2015; Becvar, et al., 2018; Saupe, et al., 2015). Such content can also be donated by Peer Leader alumni and supportive non-institutional 
affiliates. We share and endorse this relatively simple strategy of DIY PLTL, self-funding your peer-assisted learning program.

\section{The process}

Developed by PLTL practitioners at UTEP, the intellectual property (IP) that Peer Leaders generate on their own time is reproduced as workbooks, and the revenue from the sales to students are returned to an autonomous local non-profit organization (Lead For America Corporation, LFAC). On their own time (off the clock as Leaders), using their own intellectual and technical resources (smart phones. tablets, laptops, etc.), the contributing Peer Leaders create and revamp workshop content and learning materials. They and other volunteers continue (since 2013) to revise and update two different 300-page PLTL workbooks every semester, which are used by students taking the first and second semester general chemistry lecture courses (Becvar, et al., 2015; Becvar, et al., 2018; Becvar, et al., 2021; Frescas, et al., 2014; Smith, et al., 2018). The students taking the courses purchase the printed workbooks that are sold through the campus bookstore..

Writing to Learn (Schmitt, 1984, Wilson, 1994; Zinsser, 1989) has taken on a new meaning. This outpouring of creativity and IP is 'Writing to Fund' the learning program. This effort at UTEP channels talent and creativity, and captures new ideas to continually transform learning materials and workshop activities. The intimate insights of the Peer Leaders have revealed their sustained awareness of the evolving minds of new generations of students. This continually helps renew and energize our PLTL program.

\section{The financing strategy}

Every semester Peer Leaders donate and assign (via signed Assignments of Rights documents) their creative content to LFAC, the non-profit organized as a United States Internal Revenue Service 501(c)(3) organization to support Peer-Led Team Learning within the educational enterprise in the United States. Presently, LFAC assembles and organizes this content into two PLTL workbooks and publishes and sells copies to university bookstores at UTEP and at the University of Texas Permian Basin (UTPB) (Becvar, et al., 2021; Ramirez, et al., 2021). In essence, profits that would go to a traditional publisher that provides books for our students, are funneled via LFAC into support for the UTEP and UTPB PLTL programs.

Every year, "royalties" from workbook sales are donated by LFAC to specific PLTLdedicated UTEP and UTPB gift accounts. The UTEP gift account supports the hourly wages of the Peer Leaders; funds a portion of the costs for Leaders to attend meetings for professional 
development; and pays minor costs for the week-long training (twice-yearly Institute for Learning) that the Leaders organize and run themselves prior to each semester's start. LFAC only donates to a specially designated university gift fund that requires all monies be solely used for the Peer Leaders, and thus precludes abuse of the funds by the university or others.

From 2012 to 2021 this process has donated more than $\$ 700,000.00$ to UTEP undergraduates. One year after its initiation, LFAC funded about half of the chemistry Peer Leaders. The percentage of Leaders supported each year has grown, such that the PLTL Program in General Chemistry at UTEP is now totally funded by this means, supporting approximately fifty Peer Leaders each fall and each spring semester.

\section{Pilot your DIY PLTL via gradual steps}

If you wish to proceed more cautiously, you may opt to use the LFAC or PLTLIS organizations, their workbooks and their help until your own program is in place. Please contact them for help getting started, as it is part of their missions. This may be a wise choice if you do not have grant funding in place, but you want to start a PLTL program, or you already have a grant and want to continue your PLTL program after the grant funding ends (Saupe, et al., 2015; Smith, et al., 2018). Enter an agreement with one of these existing nonprofit publishers to use their workbooks in your program.

You will need to establish a dedicated gift fund at your institution to handle the finances and keep you out of Conflict-of-Interest difficulties. A major portion of the "royalties" from the sale of these workbooks will be returned to your PLTL gift fund to pay program expenses.

At UTEP in 2021, we pay our Peer Leaders \$8.50/hour for ten hours (two two-hour workshops) a week. This wage also includes Leader weekly meetings with the professors, an office hour, etc. For the fifteen-week fall and spring semesters, this requires funding of about $\$ 1,275$ per Leader per semester. Our workshop size is $12-15$ students per workshop. To adequately offset the cost of paying Leaders, the current "royalty" needed per workbook is about $\$ 45$ to $\$ 50$. Although at UTEP we find that Leader salaries incentivize professional growth, your program will have its own structure and motivations. However, a reliable source of funding can clearly benefit any program.

As described above, this royalty obtained per workbook sold is paid by each student who buys a workbook for the course workshop. At UTEP, PLTL workshops are a required part of the general chemistry curriculum. By working through LFAC, instead of supporting traditional publishers or yourself as an author, these DIY royalties are redeployed to support much needed PLTL programs. As a stakeholder in this DIY PLTL strategy, you have to choose a charitable cause that will most benefit your students. You relinquish your gains as a potential 
author for the benefit of your students, your Leaders, and the overall success of the program. We find that it is well worth the choice.

To ensure the funding raised matches the cost needed every semester, "used" workbooks cannot be an option for students. Workbooks are designed, with study problems to be worked out on the paper pages, and with tear-out homework pages and summary tables. In addition, the LFAC strategy to prevent 'used' workbooks from depleting the funding stream is to update and change the content, to modify some of the formatting, and to vary the color of the paper for printing the new workbooks every semester (Avitia, et al., 2021). This insures continual, sustained involvement, and purchase of the current product. The challenge of producing revised or new material each semester is a continual responsibility; however, this is readily accomplished by a Workbooks Revision subcommittee made up of Peer Leaders eager to have their name and authorship recognition in the Contributors section in the front of each new edition. Based on your budget needs, an annual workbook edition may be a viable option. The final edits and quality checks are made by the publisher, LFAC, and supportive professors and contributors.

\section{Establish your own Non-Profit}

Once you have a PLTL program in place, and once you have willing Leaders capable of producing IP, you might want to establish your own local non-profit to continue the funding-generation process. For a 501(c)(3) in the United States, you will need to form a Board of Directors and be prepared to file IRS Form 990 each year to maintain legal nonprofit status. To get the legal process started, choose a unique name and use IRS Form 1023 to apply for non-profit status. Again, LFAC and PLTLIS will offer help if requested.

\section{$\underline{\text { Creativity unleashed }}$}

Once Peer Leaders are encouraged to develop their intellectual power, they naturally expand their creative and innovative efforts in new directions to generate scholarly output that supports learning. Figure 1 shows the number of conference presentations on learning submitted by UTEP Peer Leaders during the period from 2002 to 2019. Because of COVID19 restrictions, this level of production came crashing to a halt in 2020 but resumed in 2021 as the Leaders learned and adopted video production (Becvar, et al., 2021; Martinez, et al., 2021). Seeing and sensing the need, UTEP Leaders in 2018 initiated a trend to create new printed learning materials just for Leaders to support student-facilitated learning; Alfsen, et 
al. (2019) produced an 'activities guide' to use specifically in coordinating first semester General Chemistry workshops.

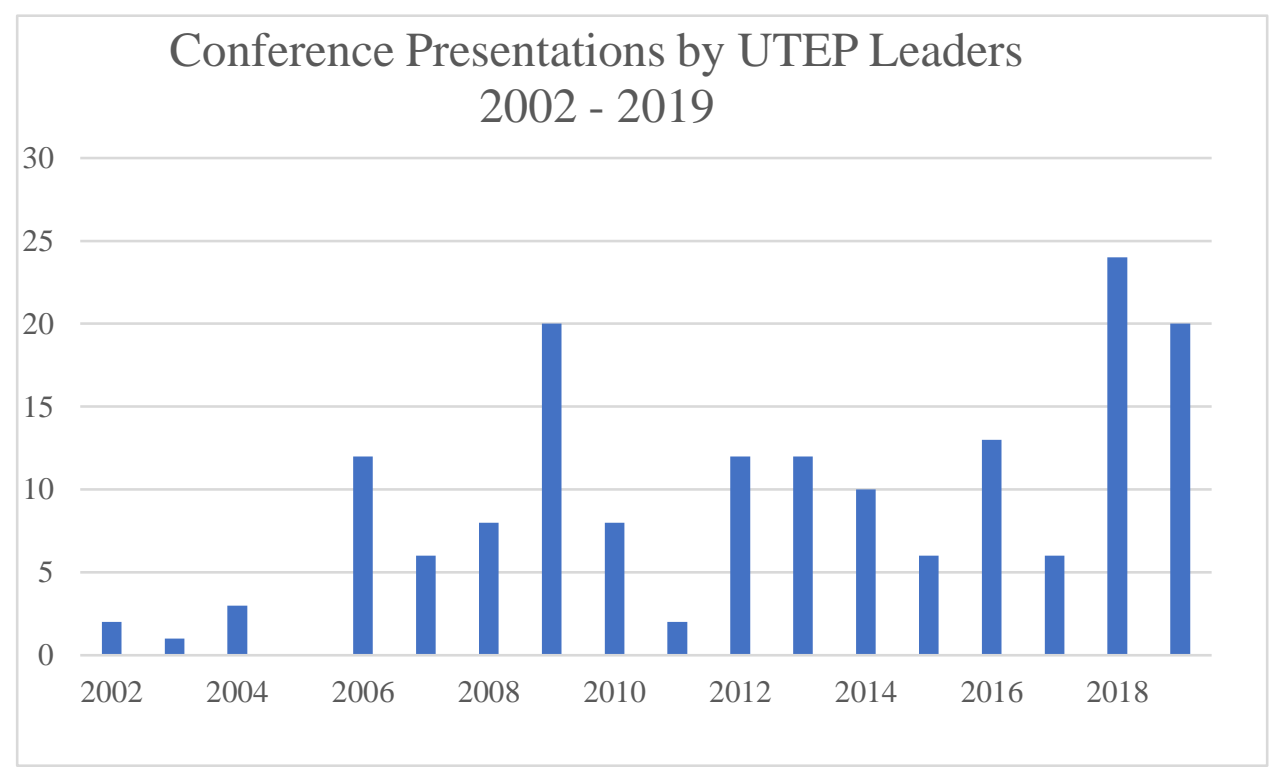

Figure 1. Number of Presentations by UTEP Peer Leaders Each Year, 2002 - 2019

\section{History}

How did this remarkable DIY PLTL process get started? The facilitated learning intervention in chemistry at UTEP began in 2000 by incorporating the already established PLTL program (Gosser \& Roth, 1998; Roth, et al., 2001) with funding from an NSF Model Institutions of Excellence grant (Flores, 1997) to introduce PLTL into first semester general chemistry (Becvar, 2012). Later, an NSF STEM Talent Expansion Program (STEP) grant entitled "Integrated Science Teaching and Retention (I-STAR)" (Becvar, et al., 2007) expanded PLTL into second semester general chemistry and temporarily into courses in other disciplines. When this second NSF grant was nearing an end, the great recession of 2008 occurred and our university's finances and all funding agencies were on pause. We were looking at the forced termination of our very successful PLTL program.

Yet the benefits of PLTL interventions were clear so staunch faculty members explored ways to keep the peer-facilitated learning intervention. During a brainstorming moment, we came up with the idea of creating a workbook to aid and guide the implementation of the PLTL workshops, with the possible benefit of supporting the program financially. It was a worthwhile experiment. So, initially, the PLTL faculty-authored the workbooks (Becvar et al., 2012a; Becvar et al., 2012b). After one iteration, this strategy was halted, because 
University of Texas System rules prohibit faculty-authored materials to be sold in the university bookstore for a profit; this rule was established to eliminate any Conflict of Interest.

Through the creation of the LFAC non-profit, the Peer Leaders and other contributors provided a legitimate alternative. The authorship would be theirs. Each contributor assigns their Intellectual Property via an Assignment of Rights form to LFAC. Because these capable facilitators became familiar with the course content, sequence of topics, and specific difficulties their students face, the Peer Leaders themselves began to generate relevant texts, helpful discussions, and chemistry problems for each of the two courses in general chemistry. These authors create and revise content every semester, and the workbooks have grown from about 100 pages to over 300 pages since 2013 .

\section{$\underline{\text { PLTLIS enhancement of DIY }}$}

Described above is Do It Yourself PLTL - in general chemistry. In 2015 the National Science Foundation (NSF) supported an I-CORPS — L grant that proposed this DIY financial process, based on the UTEP model (the diagram in Figure 2 shows the overall strategy). Team SUSTEM from UTEP proposed a strategy for widespread use (Saupe et al., 2015). This expansion of the DIY model was undertaken by the Peer-Led Team Learning International Society (PLTLIS, see http://www.pltlis.org/), another nonprofit organization that the authors helped establish to provide support, training, and guidance to PLTL programs everywhere.

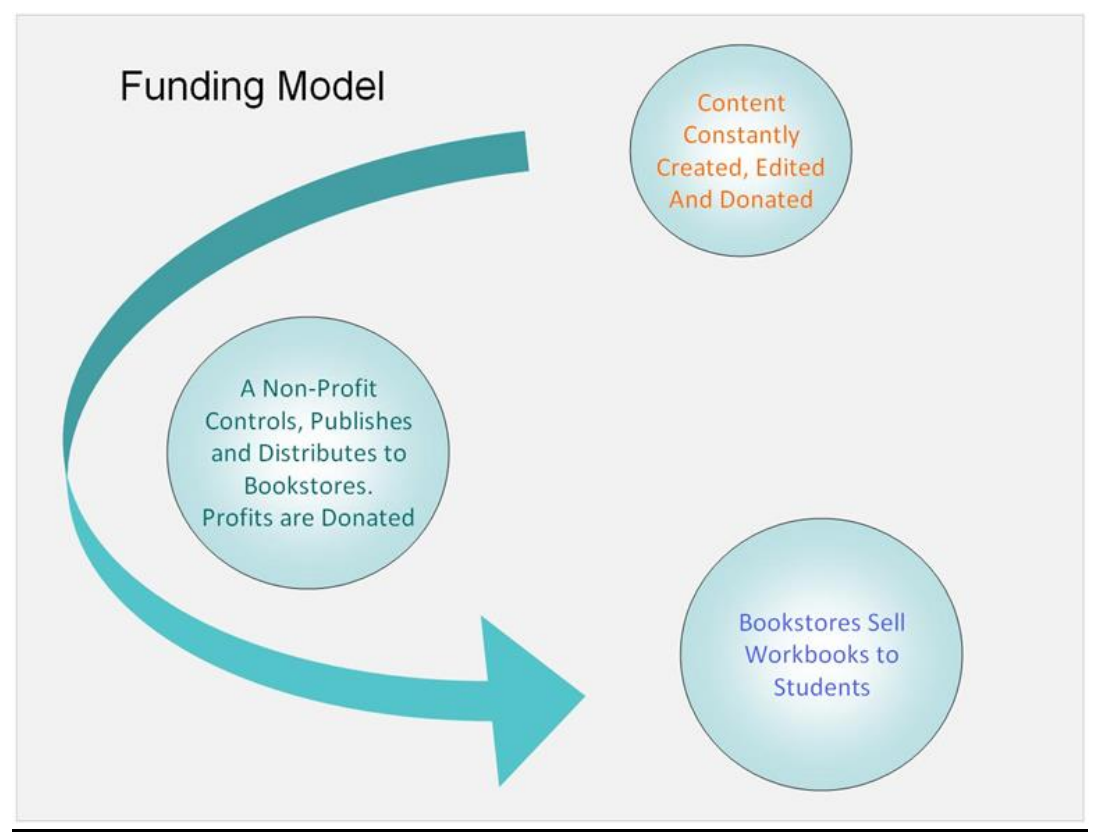

Figure 2. The Funding Strategy of DIY PLTL (Saupe, et al., 2015) 
PLTLIS has now begun providing workbooks to support PLTL for various disciplines (https://shop.pltlis.org). These materials include a guide to facilitation techniques for generic collaborative team-based learning (McWilliams, et al., 2019); and its companion, translated into Spanish (McWilliams, et al., 2020).

What is the downside?

What are the possible downsides in implementing DIY PLTL? There are basically two so first consider the simpler. By choosing to use ready-made workbooks, such as those from LFAC and PLTIS, your personal responsibility is minimized, as most of the work has been done for you. You just need to designate quantities for the bookstore and coordinate with the publisher. However, fewer funds will be donated to your program, so you may need to supplement your funding by other means or reduce your Leader salaries. The bookstore sells the books, and your PLTL program receives a donation from the publisher.

The second is that you decide to create and publish your own customized books and maximize your program benefits as previously discussed. However, the work and time involved is greater. The periodic workbook revisions and updates can, for the most part, be handled by your group of volunteer Leaders, but you will need to consistently direct and monitor the work to ensure appropriate progress. Perhaps you can try spreading out revisions by periodically working on each book section throughout the semester. Most of the commitment in work and time is in reviewing the book's final draft and ensuring adequate quality and accuracy. This may take a few days out of your summer and depends on how refined the book has become. You will need to provide your local printer with the required files, and coordinate quantities ordered and delivered so they match your institution's needs. Collaborators, like other colleagues or especially motivated students (sometimes graduates), can help alleviate this workload.

Your future - if you choose it

All the creative writing opportunities resulting from DIY PLTL develop and support innovation, entrepreneurship, and self-determination in students. Once your Peer Leaders embrace this creative IP-generation prowess, they will reap the results and so will your program. DIY PLTL perpetuates itself and funds your program year after year. We encourage you to learn how you can promote the endeavors of your talented Peer Leaders and support PLTL on your campus. Undergraduates, in any form of peer-facilitated leadership, can be a vital part of the DIY PLTL process; the success of the UTEP program has 
demonstrated this. Please feel free to contact the authors for legal documents such as Bylaws or Assignment of Rights documents. Other suggestions include:

- Use existing materials as a starting point.

- Establish a dedicated Gift Fund and a process to pay your Leaders. This will involve working with various institutional offices.

- Revise the course curriculum to put Peer-Led Workshops into place.

The program at UTEP is currently being supported by DIY PLTL because the workbook is an integral part of the program, and the workbook is required for the courses using PLTL. However, the required workbook is not necessary for you to benefit from the DIY PLTL approach. Such a strategy can be applied to a variety of learning materials, which may be optional purchases for students. Optional materials such as help manuals, homework practice problem sets, strategies for success, lab manuals, and other useful materials can still be created and made available through bookstores and other venues. The proceeds can then be used to support and enhance your peer-assisted learning program, which is the whole point of DIY PLTL. Join with other advocates on your campus to unfold a secure and sensational future that promotes Peer-Led Learning.

\section{References}

Alfsen, A., Antohi, E., Baker, A., Campos, M., Ramirez, A., Becvar, J. E., and Saupe, G. (2019). First Semester General Chemistry: Resource Book for Peer-Led Team Learning in Workshops. El Paso, TX: Lead For America Corporation Press.

Amaya, A., Becvar, J.E. (2012). Tres Caballeros: A Learning Strategy for "Plus Two" Peer-Led Team Learning. Peer-Led Team Learning: Leader Training. Online: https: / / pltlis.org/wp-content/uploads/2012/10/Games-PLTL-Leader-TrainingUTEP-Three-Caballeros-Amaya.pdf

Avitia, K., Melendez, C., Aragonez, R., Delgado, S., Tipo, J., Olivas, M., Saupe, G., and Becvar, J.E., (2021). Changing the Learning Facilitation Workbook Each Semester, Texas Academy of Science, [Video]TouTube. https: / / youtu.be/8djuHif1HsE

Azam, A.G., Vasquez, B., Lopez, E., Becvar, J.E. (2012a). CHEMTwister. Peer-Led Team Learning: Leader Training. Online https: / / pltlis.org/wpcontent/uploads/2012/10/Games-UTEP-CHEMtwister-Azam-Vasquez-Lopez.pdf 
Azam, A.G., Vasquez, B., Lopez, E., Becvar, J.E. (2012b). CHEMTaboo. Peer-Led Team Learning: Leader Training. Online: https: / / pltlis.org/wpcontent/uploads / 2012/10/Games-UTEP-CHEMTaboo-Azam-Vasquez-Lopez.pdf

Azam, A.G., Vasquez, B., Lopez, E., Becvar, J.E. (2012c). CHEMJeopardy. Peer-Led Team Learning: Leader Training. Online: https://pltlis.org/wpcontent/uploads/2012/10/Games-UTEP-CHEM Jeopardy-Azam-Vasquez-Lopez.pdf

Becvar, J.E. (2012). Two plus two equals more: Modifying the Chemistry curriculum at UTEP. Peer-Led Team Learning: Implementation. Online: https://pltlis.org/wpcontent/uploads / 2012/10/Implementation-Various-Campuses-Becvar-UTEP-TX.pdf

Becvar, J., Dreyfuss, A.E., Flores, B.C., and Dickson, W.E. (2008). Plus Two: Peer-Led Team Learning improves student success, retention, and timely graduation, 38th ASEE/IEEE Frontiers in Education Conference, T4D: 15 - 18.

Becvar, J. E., Dreyfuss, A. E., Montes, M., Saupe, G., Narayan, M., Avitia, K., Martinez, E., Melendez, C., Najera, J., \& Tepezano, E. (2021). Workbooks Support Professional Development of Undergraduates. International Forum for Peer Learning, Lund University, Sweden. [Video]YouTube. https: / / www. youtube.com/watch?v=L4 ev0Ynuv4.

Becvar, J. E., Flores, B., Knaust, H., Lopez, J., \& Tinajero, J. (2007). Integrated Science Teaching and Retention (I-STAR), NSF DUE grant 0653270.

Becvar, J. E., Narayan, M., Noveron, J. C., \& Saupe, G. (2012a). Chemistry by Exploration: Second Semester General Chemistry Workbook, Peer-Led Team Learning. Hayden-McNeil, Inc.

Becvar, J. E., Noveron, J. C., Saupe, G., \& Narayan, M. (2012b). Chemistry by Exploration: First Semester General Chemistry Workbook for Peer-Led Team Learning, Hayden-McNeil, Inc.

Becvar, J. E., Noveron, J. C., Saupe, G., Dreyfuss, A. E., Gunn, B., \& Narayan, M. (2015). Developing Workbooks to Support PLTL Programs Financially. 2015 Conference Proceedings of the Peer-Led Team Learning International Society. University of Texas at Dallas, Richardson, Texas, May 28-30.

Becvar, J. E., Saupe, G. B., \& Dreyfuss, A. E. (2018). PLTL Workbooks Support Innovation in STEM Learning. 25 $5^{\text {th }}$ ACS Biennial Conference on Chemical Education, South Bend, Indiana, July 29-August 2.

Chacon, L. B., Becvar, J. E., Lee, W-Y., \& Noveron, J. (2009). Unscramble the Numbers: Peer-Led Team Learning Activity. $65^{\text {th }}$ Southwestern Regional American Chemical Society Meeting, El Paso, Texas. 
Darnell, A., Becvar, J., Flores, B., Knaust, H., Lopez, J., and Tinajero, J. (2013). Achieving Student Success Using Peer-Led Team Learning (PLTL). Conference Proceedings of the Peer-Led Team Learning International Society, New York City College of Technology of the City University of New York May 17-19, 2012. Online: https: / / pltlis.org/wpcontent/uploads/2012\%20Proceedings/PDFs/Darnell-2012.pdf

Deemer, E.M., Hernandez, J.E. \& Becvar, J.E. (2012). Adapting the 'Three Man' game scenario as a collaborative learning strategy in chemistry. Peer-Led Team Learning: Leader Training. Online: https://pltlis.org/wp-content/uploads/2012/10/GamesUTEP-Three-Man-Game-Deemer-Hernandez.pdf

Dreyfuss, A.E., Villatoro, M., Loui, M. C., Becvar, J. E., Saupe, G. B., \& Johnson, W. C. (2015). Getting Past the First Year: Retaining Engineering Majors. Proceedings of the $45^{\text {th }}$ ASEE/IEEE Frontiers in Education Conference, S3D: First and Second Year Topics III(3) 1 6. October 21-24.

Frederick, J., \& Becvar, J.E. (2012). Chemical Speed Dating as a Peer-Led Team Learning Activity. Peer-Led Team Learning: Leader Training. Online: https: / / pltlis.org/wp-content/uploads/2012/10/Games-UTEP-Chemical-SpeedDating-Frederick.pdf

Flores, B. (1997). MIE: The University of Texas at El Paso: A Model of Excellence NSF grant 9550502 .

Frescas, B., Marin, J., Noveron, J. C., Saupe, G., Narayan, M., Gunn, B. M., \& Becvar, J. E. (2014). Workbooks Fund and Organize Peer-Led Workshops, Third Annual Conference of the Peer-Led Team Learning International Society, California State University - Dominguez Hills, Carson, California, May 29-31.

Gosser, D. K., \& Roth, V. (1998). The Workshop Chemistry Project: Peer-Led Team Learning. J. Chem. Ed., 75, 2, $185-187$.

Guzman, R., Nieto, Z., Ayala, J., Becvar, J. E., Saupe, G., \& Lee, W-Y. (2016). Kings and Queens of Chemistry Learning. Fifth Annual Conference of the Peer-Led Team Learning International Society, San Jose City College, San Jose, California.

Kerstiens, C. G., Sisniegab, D. C., Gomez, A., Gunn, B. M., Becvar, J. E., \& Narayan, M. (2017). Untangling chemical kinetics through tangible and visual representation of matter. African Journal of Chemical Education, 7, 1, 37 - 45. 
Llanes, L.G., Johnson, J.L., Hernandez, J.E., \& Becvar, J.E. (2012). General Chemistry Mnemonics and Shortcuts. Peer-Led Team Learning: Leader Training. Online: https: / / pltlis.org/wp-content/uploads/2012/10/Games-UTEP-Mmnemonics-LlanesJohnson-Hernandez.pdf

Martinez, E., De la Hoya, D., Ibarra, L., Najera, J., Boyea, A., Narayan, M., Saupe, G. B. \& Becvar, J.E. (2021). Video Editing: A Valuable Tool to Enhance Peer-Led Team Learning for Remote Learning, Texas Academy of Science. On-Line. [Video] YouTube: https: / / youtu.be/Hy281Grr oA.

McWilliams, A. L, Dreyfuss, A. E., \& Becvar, J. E. (2019). Facilitating Team-Based Learning: A Peer Leader's Guide to Leading Learning Activities, Peer-Led Team Learning International Society Press, www.pltlis.org, ISBN 978-1-944996-04-8.

McWilliams, A., Dreyfuss, A.E., Becvar, J. E., translated by Carbajal-Ida, D. I., Fraiman, A., Marin, M. S., Moreno, C. J., Tepezano, E., \& Torres, P. R. (2020). Facilitando el Aprendizaje en Equipos:Una Guía de ayuda al Líder de Grupo para Facilitar Actividades de Aprendizaje. Peer-Led Team Learning International Society Press, www.pltlis.org, ISBN 978-1-944996-05-5.

Moreno, S., Saupe, G. B., \& Becvar, J. E. (2013). Vision and Change: Enabling Student Success via Peer-Led Team Learning. Second Annual Conference of the Peer-Led Team Learning International Society, University of Houston-Downtown, Houston, Texas, May 30-June 1 .

Orozco, C., Becvar, J. E., \& Narayan, M. (2018). A toolkit for mastering organic nomenclature in general chemistry. African Journal of Chemical Education, 8, $24-33$.

Ramirez, A., Rodriguez, M., Montalvillo, F., Muniz, J., Montes, M., Saupe, G., and James E. Becvar, J.E. (2021). Doubling Down on Online Education: Establishing a CrossUniversity Collaborative Environment to Promote Peer Learning and Networking, International Forum for Peer Learning, Lund University, Sweden, [Video]YouTube. https: / /youtu.be/fnWF_Zb5sNA

Ramirez, C., Ronquillo, L., Llanes, L. L., Amaya, A. M., Ulloa, N., \& Becvar, J. E. (2009). Why games should be integral to Peer-Led Team Learning. 237th American Chemical Society National Meeting, Salt Lake City, Utah.

Ramirez, P., Carrillo, D., Boyea, A., Ayala, J., Rubio, P., Corral, R., Chavez, C., Priego, A., Lazarski, A., Rodriguez, J., Lee, W-Y., \& Becvar, J. E. (2016). ChemisTri-naming. Fifth Annual Conference of the Peer-Led Team Learning International Society, San Jose City College, San Jose, California. 
Ramirez, P., Gallegos, M., Ponce, A., Boyea, A., Chavez, A., Becvar, J. \& Noveron, J. (2017). Illustrated Storytelling for Enhanced Learning in STEM in a PLTL Environment. Sixth Annual Conference of the Peer-Led Team Learning International Society, Northeastern Illinois University, Chicago, Illinois.

Roth, V., Goldstein, E., and Marcus, G. (2001), Peer-Led Team Learning: A Handbook For Team Leaders. Upper Saddle River, NJ: Prentice-Hall, Inc.

Saupe, G. B., Dreyfuss, A.E., Becvar, J. E., \& Johnson, W. C. (2015). I-Corps L: Sustainability of Peer-Led Learning through a Commercialization Model, Team 18 SusTEM, National Science Foundation, NSF- I-CORPS L Grant.

Schmitt, N.A. (1984). Writing to Learn. Nurse Educator, 9, 2, 43-45. Summer. https: / /journals.lww.com/nurseeducatoronline/Abstract/1984/09020/WRITING_T O_LEARN.15.aspx

Smith, M., Belmont, A., Priego, A., Baker, A., Narayan, M., Saupe, G., \& Becvar, J. E. (2018). Sustaining Student Facilitated Learning Via A Workbook - Ending The Cycle Of Grant Dependency. $121^{\text {st }}$ Texas Academy of Science Annual Meeting, Midland, Texas.

Ulloa, N., Becvar, J.E. (2012). Integrating the Guess ChemWho Game into Peer-Led Workshops. Peer-Led Team Learning: Leader Training. Online: https: / / pltlis.org/wpcontent/uploads / 2012/10/Games-UTEP-Guess-ChemWho-Game-Ulloa.pdf

Wilson, J. W. (1994). Writing to learn in an organic chemistry course. J. Chem. Ed. 71, 12, 1019-20.

Zinsser, W. (1989). Writing to Learn: How to Write - and Think - Clearly About Any Subject at All. Longman Higher Education.

Zonoozi, F., Narayan, M., \& Becvar, J. E. (2013). Foundation of the Leaders, by the Leaders, and for the Leaders. 2012 Conference Proceedings of the Peer-Led Team Learning International Society, New York City College of Technology of the City University of New York. Online: https://pltlis.org/wpcontent/uploads/2012\%20Proceedings/PDFs/Zonoozi-2012.pdf 